\title{
Exploration and Study on the Run-Through Cultivation of High-End Technical Skilled Talents in Beijing
}

\author{
XiuHua Geng ${ }^{\mathrm{a}}$, Xianzhen Ren ${ }^{\mathrm{b}, *}$ and Zhibin Zhang ${ }^{\mathrm{c}}$ \\ Software and Information Department Department, Beijing Information Technology College, China \\ "Corresponding author.Email: "Xianzhen Ren; ${ }^{a}$ gengxh@bitc.edu.cn; ${ }^{b}$ rxz90@126.com;czhangzb@bitc.edu.cn.
}

\begin{abstract}
It has been more than three years since the implementation of the run-through cultivation in Beijing. Regarding how to truly cultivate high-end technical talents that meet the needs of the society, all schools are in the stage of learning, exploring, advancing, and improving. The primary task of the basic teaching curriculum for the run-through cultivation lies in how to meet the continuity and curriculum connection, that is, the curriculum must not only meet the needs of the high school stage, but also connect the students' courses at the higher vocational and undergraduate levels. This paper mainly studies several key issues that need to be resolved in the run-through cultivation project of high-end technical talents in Beijing, and analyzes the specific content, goal and implementation plan of the run-through cultivation.
\end{abstract}

Keywords: Run-through cultivation, High-end technical talents.

\section{INTRODUCTION}

The run-through cultivation for High-end Technical and Skilled Talents in Beijing is a project (Hereinafter referred to as run-through cultivation) implemented by the Beijing Municipal Education Commission since 2015. There are four categories of the run-through cultivation: one is the high-end technical skills talent training project, the second is the non-common language foreign language talent training project, the third is the preschool education and basic education teacher training project, and the fourth is the school-enterprise in-depth cooperation High-end talent training project. All candidates who have the qualifications to enter a higher school can apply for the formal household registration in Beijing. The run-through cultivation school system is seven years, and the " $2+3+2 "$ school system training mode is adopted. The first two years are based on higher vocational colleges, and the model high schools provide teachers, teaching materials and other re-sources for collaborative training; the middle three years mainly rely on higher vocational colleges training; in the next two years, students can choose to enter the domestic under-graduate education stage through the college entrance examination or apply for the rele-vant foreign partner colleges to enter the foreign undergraduate education stage, and they can obtain a diploma issued by domestic or foreign undergraduate colleges if they pass the test.
The run-through cultivation project takes Beijing's key higher vocational colleges and secondary vocational schools as the enrollment unit, and cooperates with undergraduate universities and domestic and foreign enterprises to select superior majors for industrial development and carry out higher vocational education and undergraduate professional education. The training of high-end technical and skilled talents is a systematic project, involving many factors such as the concept, system, teacher base, the design and implementation of talent training programs, and the evaluation of students' academic achievements in vocational education. In the enrollment plan for the 2020 through-training project announced by the Beijing Municipal Education Commission, it plans to enroll 3050 students.

\section{RELATED WORK}

In 2017, with the approval of the Beijing Municipal Education Commission, Beijing In-formation Technology College joined forces with Tsinghua University High School and Beijing Science \& Technology University to jointly carry out the high-end technical skills talents run-through cultivation project, and now open three majors-Software Technology, Information Security and Management and Big Data Technology and Application. This article takes the big data technology and application profession major 
undertaken by Beijing Information Technology College as an example to discuss.

After continuous learning and training, discussion and research, and communication with brother colleges and universities, the teacher policy, enrollment policy, talent training program formulation, curriculum arrangement and adjustment in the basic stage of the run-through cultivation have clear directions, and a more practical and feasible basic cultural education teaching plan has been formed. In September 2020, the run-through cultivation students enrolled in 2017 began to enter the higher vocational study. Therefore, it is very necessary to explore and study the talent training model through training.

This paper mainly studies several key issues that need to be resolved in the run-through cultivation project of high-end technical talents in Beijing, and analyzes the specific content, goal and implementation plan of the run-through cultivation.

\section{THE KEY ISSUES THAT NEED TO BE SOLVED URGENTLY}

\subsection{Positioning of Talent Training Goals}

The goal of talent training is the overall requirement of vocational education at all levels and types of talent training. It is a prerequisite for professional setting, curriculum development, standard formulation, and selection of teaching materials. It is the first of the top-level design of the training model.

The goal of talent training in higher vocational colleges is skill-based talents, while ap-plied undergraduate colleges belong to the high-end of the modern vocational education system, mainly engaged in professional education above undergraduate level, Therefore, the talent training objectives of higher vocational colleges and applied undergraduate colleges are two types, which are quite different.

Therefore, the first key issue that needs to be solved urgently in the run-through cultivation is how to scientifically define the goal of talent training and the specifications of talent training after the run-through cultivation, so that it is different from the previous higher vocational colleges and applied undergraduate colleges. In the process of the run-through cultivation, it is necessary to avoid the tendency of high school in the basic education stage and undergraduate education in the deepening of majors in the implementation pro-cess. Precise positioning of talent training goals is a major difficulty in implementing train-ing policies.

\subsection{Integration of the Curriculum System}

The integration of the curriculum system referred to in this paper means that in order to achieve the goal of training high-end technical skills talents, all parties involved in the run-through cultivation project carry out the overall design of the various elements of the curriculum for 7 years on the basis of mutual cooperation and around the goal of talent training, so as to realize the run-through cultivation of talents.

The curriculum as a plan and carrier for educating people is the key to achieving the goal of talent training. The talent training goal of the run-through cultivation project has been positioned as high-end technical skill talents from the beginning, and the selection of such talents does not pass the college entrance examination, directly passes the college en-trance examination to enter the domestic undergraduate program or in accordance with the requirements of foreign cooperative institutions to participate in the examination into foreign undergraduate. The particularity of this type of talent and the characteristics of examination selection determine the uniqueness of talent training.

To achieve this training goal, it is necessary to rely on a systematic and targeted curriculum system to ensure the realization of the training goal of high-end technical skills talents. Only by constructing an integrated curriculum system, the 7-year run-through cultivation project can establish the focus for the cultivation of talents at different stages of the school system, the tandem line for the cultivation of talents at different learning stages, and the combination of talent training between different training subjects.

\subsection{Formulation of Quality Evaluation System}

As a new thing, the run-through cultivation lacks a systematic evaluation system, so it is necessary to formulate a complete quality evaluation system. Only by scientifically assessing students' academic conditions can their enthusiasm for learning be stimulated, and at the same time, suitable talents can be selected and promoted to the corresponding undergraduate colleges for the next two years of study. In the process of the run-through cultivation, it is necessary to avoid the decline in the quality of talent training caused by wide entry and wide exit in vocational education in recent years, so as to complete the sacred mission of cultivating high-end technical talents for the capital.

\subsection{Exploration of Management System}

At present, no matter from the technical level or the management level, the run-through cultivation is in the exploratory stage. The process of thorough training needs to involve the three main bodies of high schools, vocational colleges and counterpart applied under-graduate colleges. The seven-year run-through cultivation is not a simple superposition and patchwork of the three stages of high school, higher vocational 
education and under-graduate education, but an optimized combination and complementary advantages of the three.

Therefore, the realization of the optimization of the through-training system must be realized through the improvement of system organization, structure and function. Only in this way can we clarify each other's work content and responsibilities, and then form an organic coordination mechanism.

\section{TRAINING GOALS AND IMPLEMENTATION PLAN}

\subsection{Training Goals}

Talent training goals determine the direction and process of talent training. Education at different levels has different talent training goals. The target orientation of talent training in higher vocational education has been in adjustment and change.

Therefore, first of all, we must establish the goal of cultivating talents through training. It is necessary for us to set a coherent basic education-higher-vocational-applied under-graduate model based on the development and reform of industrial technology structure, talent structure, and vocational education, scientifically determine the types and specifications of talent training at all levels, and accurately describe each level. The specific requirements of talents at different levels in terms of knowledge, skills, and abilities, as well as their differences, fully reflect the differences in the training objectives of education at all levels.

Second, specify the development of an integrated curriculum system.

Then, design a scientific and reasonable quality assessment system.

Finally, establish a sound management system.

\subsection{Implementation Plan}

In order to achieve the above goals, the implementation plan is as follows.

1. Establish a project team jointly participated by Beijing Information Technology College and the teachers of Beijing Science\&Technology University, which is a connected undergraduate institution of the run-through cultivation, and clarify the division of tasks.

2. Find and study relevant documents, understand policies, and summarize experience.

3.Relying on the Big Data Technology and Application major undertaken by Beijing Information Technology College, regular seminars are held to discuss the run-through cultivation talent training plan, curriculum system, curriculum standards, quality evaluation, discussion and analysis of management system, etc.

4.Track the implementation of talent training programs, curriculum systems, curriculum standards, quality assessment, management systems, etc., find problems, discuss and analyse the reasons, modify and adjust, formulate countermeasures, and form a closed loop of work.

\section{CONCLUSION}

The run-through cultivation 1 project started in 2015 is a major reform project launched by the Beijing Municipal Education Commission to explore new ways to cultivate high-end technical skills. Although the enrollment was welcomed by parents and students when it was first launched in 2015 , it was promoted in the following years. In practice, it was not as smooth as imagined, and multiple related subjects were involved in the process of the run-through cultivation, and emerging policies lacked the experience of existing reforms.

On the basis of learning from the experience of other colleges and universities undertaking the task of the run-through cultivation, we research and practice, and explore the key issues of Beijing's high-end technical and skilled personnel training model, summarize the technical path and practical experience in the realization of the run-through cultivation, in order to promote the healthy development of the effective mechanism of the run-through cultivation talent training, and improve our country's technical skills talent training system, promote the pace of vocational education reform to meet the needs of our country's economic and social development for the cultivation of highly skilled talents and provide experience and basis for reference.

\section{ACKNOWLEDGMENT}

This work is supported by Teaching reform project of Beijing Vocational Education in 2018- research and practice on the run-through cultivation of high-end technical talents in Beijing.

\section{REFERENCES}

[1] Lin Kesong, Wang Yanan. The logic, hidden worries and rational practice of the policy of "connecting China with the Chinese economy", Journal of Hebei Normal University (EDUCATION SCIENCE EDITION), 2016, 18 (3): 54-59

[2] Xu Guoqing. Curriculum convergence system: the cornerstone of modern vocational education system 
construction [J]. China Vocational and technical education, 2014 (21): 187 - 191

[3] Liu Maoxiang. Analysis of senior high school students' core literacy and school curricu-lum reform from the perspective of general vocational Communication $[\mathrm{J}]$. Vocational Education Forum, 2017 (12): 74-80

[4] Liu Yulu, Yuan Xiang, Zhang Jinfu. Practice and innovation of local undergraduate colleges actively integrating into modern vocational education system -- Taking Shanghai In-stitute of applied technology as an example [J]. China higher education research, 2015 (5): 59-63
[5] Ke Jingqiu, Shi Weiping. The policy logic, key issues and rational practice of "high-level integration", vocational education forum, 2018 (06): $86-91$

[6] Guo Chen, Zhao Xiaoyan. Construction of "integrated" curriculum system for through training [J]. China Vocational and technical education, 2017 (35): 62-67

[7] Zhou Wenqing. Construction and operation of the "four in one" talent training "Over-pass" of modern vocational education [J]. Vocational and technical education, 2018, 39 (16): 29-34 